\title{
Disturbance in seedling development of Korean fir (Abies koreana Wilson) tree species on higher altitude forests of Mt. Hallasan National Park, the central part of Jeju Island, Korea
}

Eun-Shik Kim ${ }^{1 *}$ (D), Jong-Won Lee ${ }^{2}$, Im-Joon Choi ${ }^{1}$, Wontaek Lim², Junghwan Choi ${ }^{2}$, Choong Hyeon $\mathrm{Oh}^{3}$, Sung-Hoon Lee ${ }^{4}$ and Young-Sun Kim ${ }^{1}$

\begin{abstract}
Background: Natural regeneration of seedlings as well as saplings of Korean fir has been significantly impacted by the browsing from the early stages of their development, potentially, by roe deer for the last two to three decades at the study site since late 1980s. This study was carried out to investigate current status of the disturbance in the seedling development of Korean fir (Abies koreana) on Mt. Hallasan, Jeju Island, Korea.

Methods: Field survey was carried out during June and August in 2016 to measure the characteristics of study site and understory vegetation by applying systematic sampling to 125 plots of $5 \mathrm{~m} \times 5 \mathrm{~m}$ quadrat located on eastern slope of the mountain. Correlation and regression analyses were applied to the variables quantified from the data sets using the SAS software.

Results: No saplings with their diameters at breast heights smaller than $5.0 \mathrm{~cm}$ were found at the study site indicating the serious disturbance in the natural regeneration of Korean fir at the study site. No seedlings with their heights taller than $36.0 \mathrm{~cm}$ were found at the study site indicating even more serious disturbance during earlier stage of the natural regeneration of Korean fir at the study site. A total of 616 individuals of the seedlings of Korean fir were found at 54 out of 125 sampling plots. One hundred thirty-eight seedlings (22.4\%) out of 616 individual seedlings have the vestiges for being grazed, potentially, by roe deer.

Conclusions: Due considerations should be given to the effects of browsing of the seedlings by roe deer to promote the natural regeneration of Korean fir, ultimately to restore Korean fir. It is needed for the managers of the forest to install fences around the forest area. Exclosure experiments as well as enclosure experiments of different densities of browsing should be carried out. In addition, treatment with different densities of Jeju dwarf bamboo should also be included in the experiment on Mt. Hallasan National Park, Jeju Island, Korea.
\end{abstract}

Keywords: Browsing, Disturbance, Korean fir, Regeneration, Seedling development, Roe deer

\footnotetext{
* Correspondence: kimeuns@kookmin.ac.kr

'Department of Forestry, Environment, and Systems, Kookmin University,

Seoul 02707, Republic of Korea

Full list of author information is available at the end of the article
} 


\section{Background}

Mt. Hallasan National Park is located in the central part of Jeju Island, a southernmost island in Korea, which was designated from The United Nations Educational, Scientific and Cultural Organization (UNESCO) as a UNESCO World Biosphere Reserve, World Natural Heritage and UNESCO Global Geopark (Woo et al. 2013). The summit of Mt. Hallasan is the highest peak in South Korea with its altitude of 1950 m above sea level (ASL). On higher altitude of Mt. Hallasan, there are forests dominated by Korean fir (Abies koreana) from the altitude of around $1300 \mathrm{~m}$ ASL to the summit. Korean fir is an endemic tree species to Korea (Wilson 1920, Lee 1970), and Korean fir forests are mainly distributed on Mt. Hallasan in Korea, representing the typical habitat of the sub-alpine forest of Jeju Island (Kong and Watts 1993, Song et al. 2010, Song 2011).

In Korea, Korean fir was designated as an endangered species in the national Red List by the Ministry of Environment and, also, designated as Climate-sensitive Biological Indicator Species (CBIS) (Ministry of Environment, Korea 2010, Lee et al. 2010, Park et al. 2015). The International Union for Conservation of Nature (IUCN) identified Korean fir as an endangered species in the IUCN Red List of Threatened Species (IUCN 2011).

Nowadays, we observe the decline of Korean fir forests on Mt. Hallasan. Taller trees are fallen dead blown by typhoons, which are frequent meteorological phenomena on the island. Some bigger trees are standing dead with the dieback of their branches and foliage with the reasons for the decline not well studied, yet (Kim 1994, 1996, Kim and Kim 2000, Korea Forest Research Institute 2015, Kim et al. 2016). As the trees are growing on shallow soils of volcanic bedrock, older trees are more vulnerable to wind fall and drought than younger trees. Aging can be the major predisposing factor that can increase the sensitivity of the old trees to strong winds accompanied by the frequent typhoons and to droughts with soil water quickly infiltrated to volcanic rock and easily drained from the soil. Therefore, local people observe Korean fir trees on the mountain live only 100 years and die. In fact, tree species of fir (genus Abies) are generally a short-living tree species. So, seeing the decline of old fir trees may not be so strange phenomena to observe on the mountains throughout the world (Sprugel 1976, Kohyama 1988).

A serious phenomenon observed on Korean fir forests is that there are almost no saplings of Korean fir with their diameter at breast heights (DBHs) less than $5 \mathrm{~cm}$ regenerated from the forests on the mountain (Kim et al. 2016). This indicates that the natural regeneration of Korean fir is being severely disturbed at Korean fir forests and also suggests that seedling development in earlier stage could also have been disturbed seriously.
Currently, there are a few studies in describing the current status of the seedling development of Korean fir on the forest (Koh et al. 1996, Kim and Choo 2000, Kim et al. 2007b, Song et al. 2010, 2014). Many studies reported the disturbance of regeneration of tree species by ungulate browsing around the world (Wilson 1969, Gill 1992, Waller and Alverson 1997, Potvin et al. 2003, Rooney and Waller 2003, Senn and Suter 2003, Weisberg and Bugmann 2003, Cote et al. 2004, Tsujino and Yumoto 2004, Pepin et al. 2006, Takatsuki 2009, Hidding et al. 2012, Nagaike et al. 2014; Cutini et al. 2015, Swiss Federal Institute for Forest 2015); a few studies were carried out on the dynamics and the other ecological issues of roe deer in Korea (Kim and Kim 2001, Kim 2006, Kim and Hong 2006, Kim et al. 2007a, Jeon and Kim 2011, Jo et al. 2012, Kim et al. 2012, 2013, Kang 2013, Lee et al. 2015). In addition, studies on the dynamics of forest stands indicated that competition with other species of understory vegetation such as dwarf bamboo (genus Sasa) can interrupt the establishment of the seedlings of the natural tree species at forest stands of the world (Nakashizuka 1988, Peters et al. 1992, Abe et al. 2001, 2002, Taylor et al. 2004, 2006, Doležal et al. 2009, Song et al. 2014).

In order to understand what is happening in the natural regeneration and the disturbances in the natural regeneration of Korean fir trees species on Mt. Hallasan National Park, there are issues to address related to the regeneration of Korean fir on higher altitude forests of Mt. Hallasan National Part such as the following:

- The patterns of regeneration of the seedlings of Korean fir;

- The mechanisms of the disturbance in the natural regeneration of the seedlings of Korean fir;

- The major and/or potential causes for the disturbances in the natural regeneration of the seedlings including roe deer and Jeju dwarf bamboo (Sasa quelpaertensis Nakai);

- The magnitude of the seriousness of the problem of the disturbance of natural regeneration of Korean fir;

- Measures to reverse this kind of disturbance in regeneration of Korean fir tree species on Mt. Hallasan National Park, Jeju, Korea.

This study was carried out to address the issues suggested above by investigating the current status of the lower story vegetation of Korean fir forests. By this, we are expecting that the results of this study could give important clues in understanding current status of the regeneration, the problems in disturbing the regeneration, and potential clues for overcoming the problems in the regeneration of Korean fir on Mt. Hallasan, Jeju Island, Korea. 


\section{Methods}

\section{Study area and sampling}

The study area is represented by the sub-alpine forest dominated by Korean fir with the altitude between 1520 and $1640 \mathrm{~m}$ ASL located at the eastern slope near the Jindallaebat Shelter of Mt. Hallasan National Park, Jeju Island, Korea (Fig. 1). At the study site, Korean fir is the dominant tree species at the tree layer. Specifics of the vegetation composition including shrub layer and herbaceous layer are suggested by Kim et al. (2016) and Lee (2016). The size for the study site is 5 ha. This study site is subdivided by 125 plots of $20 \mathrm{~m} \times 20 \mathrm{~m}$ quadrat. For each plot of $20 \mathrm{~m} \times 20 \mathrm{~m}$ quadrat, a systematic sampling was applied to $5 \mathrm{~m} \times 5 \mathrm{~m}$ quadrat to survey understory vegetation. Field survey was carried out from June to August in 2016.

\section{Field survey and statistical analysis}

\section{Identification of a seedling of Korean fir in size}

Although there are different definitions in identifying the seedling of a tree species, a seedling is defined as a small tree germinated from seed but smaller than a sapling, meanwhile a sapling is defined as a usually young tree larger than a seedling but smaller than a pole, whose size varies by region (Helms 1998, Kerr et al. 2002, Kerr and Mackintosh 2012). In this study, a seedling is identified as a small tree whose DBH is smaller than $2 \mathrm{~cm}$ and a sapling is identified as a tree whose $\mathrm{DBH}$ is equal to or larger than $2 \mathrm{~cm}$ and smaller than $10 \mathrm{~cm}$, whose differentiation was adopted by Kim et al. (2016).

\section{Vegetation characteristics of the seedlings of Korean fir}

Vegetation characteristics of the seedlings of Korean fir such as the frequency and the number of seedlings were surveyed for each of the sampling plots and the height of each of the seedlings was also measured.

\section{Estimation of the age of Korean fir seedlings}

The age of each seedling was estimated by observing the number of nodes between bud scale scars on the stem. Estimated age of the seedling was used as a reference to

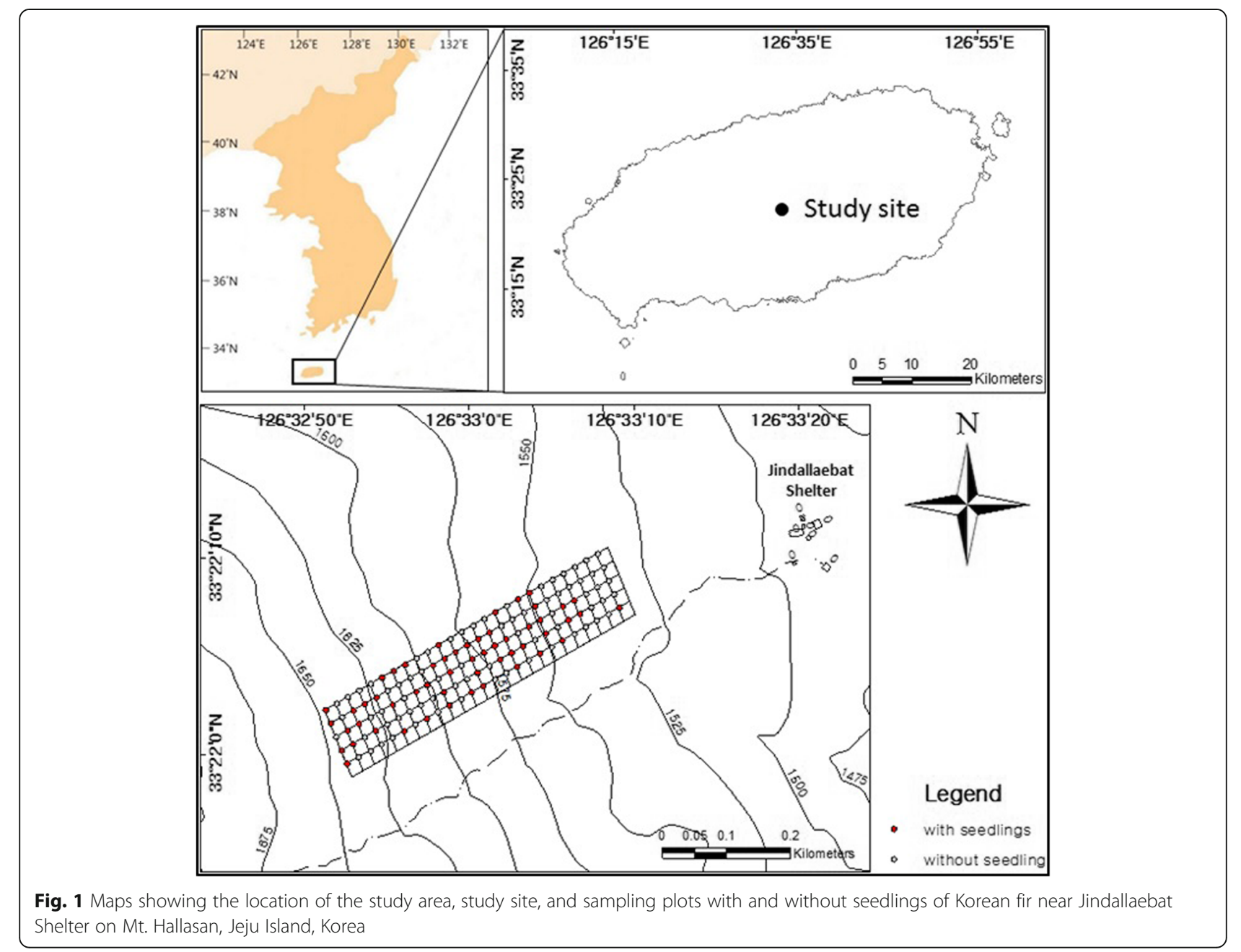


determine the rate of height growth of the seedlings and as the time scale in describing the processes being occurred at the study site.

\section{Vegetation characteristics of the population of Jeju dwarf bamboo}

Vegetation characteristics of the population of Jeju dwarf bamboo such as the coverage and the average height of the population were surveyed for each of the sampling plots.

\section{Measurement of site environmental characteristics}

To check the effects of site environmental factors on the occurrence of the seedlings of Korean fir, such factors as the rates (\%) of rock exposure and canopy gap and slope $\left(^{\circ}\right)$ were measured for each of the sampling plots.

\section{Data analysis}

Using the Statistical Analysis System (SAS) software, correlation and regression analyses were applied to the variables quantified from the data sets measured through the field survey.

\section{Results and discussion}

Occurrence of the seedlings of Korean fir at the sampling plots

Frequency distribution and the disturbance in the seedling development of Korean fir by height

When the occurrence of seedlings of Korean fir was investigated at 125 sampling plots of $5 \mathrm{~m} \times 5 \mathrm{~m}$ quadrat, there were several points of interests to notice.

Most of all, it is quite striking to note that there was no sapling of Korean fir with its height growing taller than breast height $(1.3 \mathrm{~m}-1.4 \mathrm{~m})$. More strikingly, there was no seedling of Korean fir with its height taller than
$36 \mathrm{~cm}$ in height. These not only indicate that the early stage of natural regeneration of Korean fir has been severely disturbed but also imply that the succession of Korean fir forest is being halted at the study site.

There are only 616 seedlings found from 125 sampling plots of $5 \mathrm{~m} \times 5 \mathrm{~m}$ quadrat. The frequency distribution of the seedlings by height is illustrated in Fig. 2 .

It is quite striking to note that there are almost no seedlings with their height taller than $12 \mathrm{~cm}$ with exceptions of those with their height in $15 \mathrm{~cm}$ (1 seedling), $16 \mathrm{~cm}(2$ seedlings), and $35 \mathrm{~cm}$ (1 seedling). In addition, $94.6 \%$ of the seedlings are with their height in between 2 and $7 \mathrm{~cm}$ and $74 \%$ of them are with their heights in between 3 and $5 \mathrm{~cm}$. Average height of the seedlings is $4.4 \mathrm{~cm}$.

It is quite surprising to see that the numbers of seedlings with their height in 1 and $2 \mathrm{~cm}$ are very small, 10 and 37, respectively. While this may indicate that some phenomena disturbing the natural development of seedlings of Korean fir have happened very recently at the study site, it is quite important to note that there are young seedlings, still, being regenerated from the study site, however. It is quite interesting to note that the number of seedlings begins to drop very dramatically from $5 \mathrm{~cm}$ in height for the young seedlings.

It is also interesting to note that 138 seedlings (22.4\%) out of 616 seedlings have the damages with vestiges for being grazed, potentially, by roe deer (Fig. 3). It is also surprising to note that the young seedlings with their height taller than $2 \mathrm{~cm}$ have the damages in the stem tips (Fig. 2), which indicates that the seedlings are very vulnerable to continuous browsing, potentially, by roe deer from early stage of their development.

During the field survey, the authors found the big seedlings with their height about $50-60 \mathrm{~cm}$ tall whose

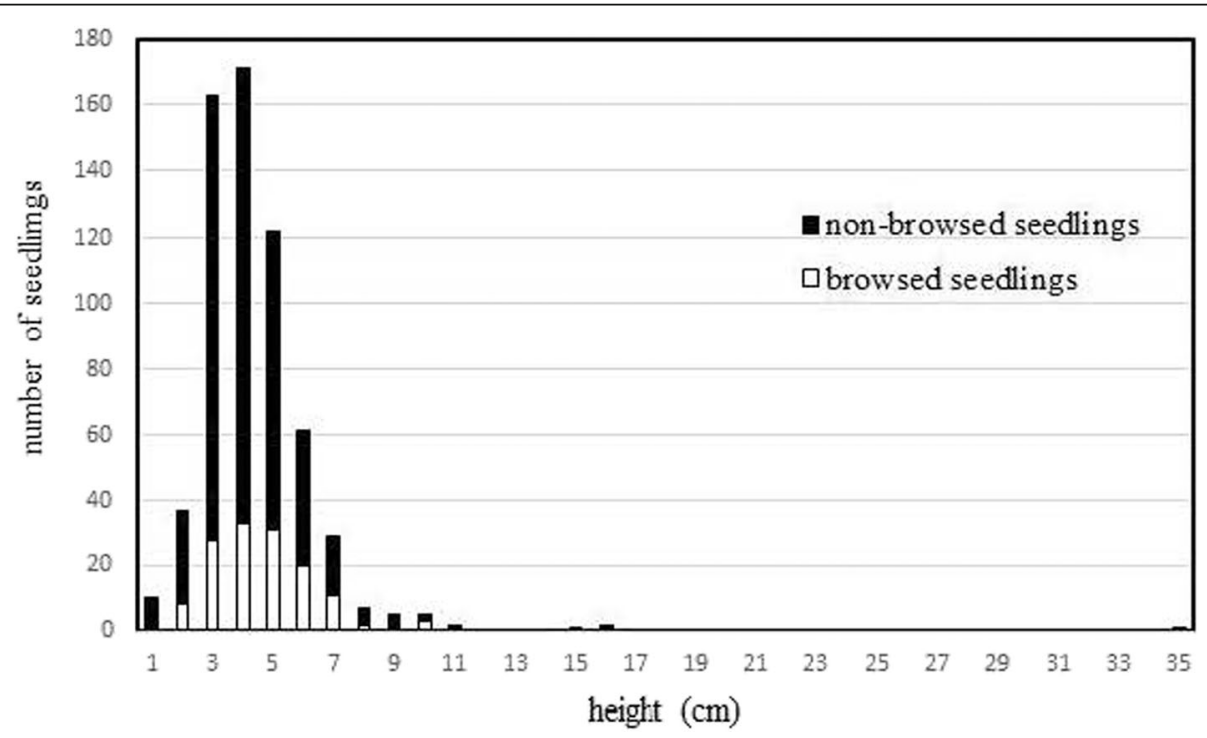

Fig. 2 Frequency distribution and the disturbance in the seedling development of Korean fir by height 

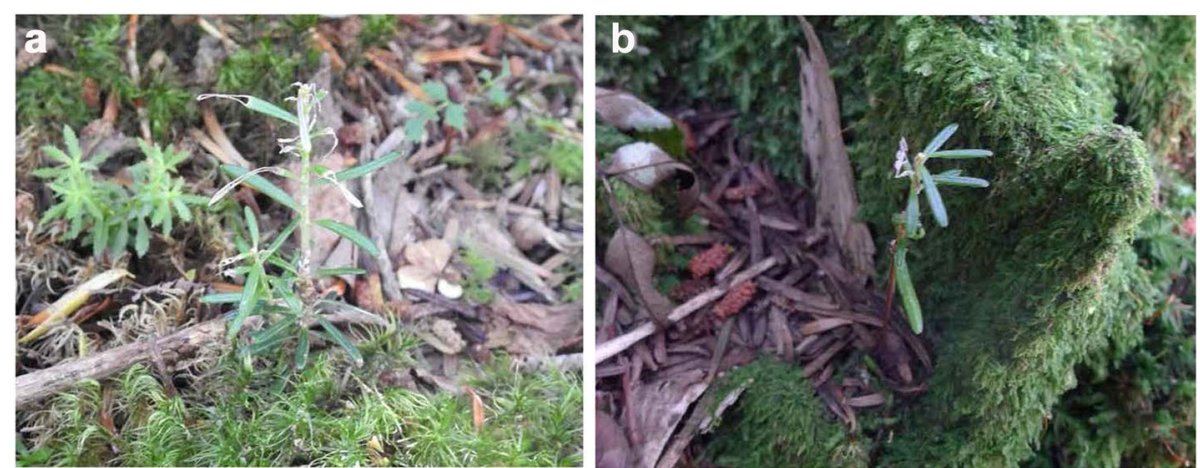

Fig. 3 a A photo showing the damages on the stem tips of the seedling, potentially, browsed by roe deer at the study site (23 July 2016 , photo by Jong-Won Lee). $\mathbf{b}$ A photo showing the damages on the stem tips of the seedling, potentially, browsed by roe deer at the study site (23 July 2016, photo by Jong-Won Lee)

step tips have been browsed, potentially, by roe deer, around the sampling plots (Fig. 4).

There are scattered information on the density of roe deer on Mt. Hallasan National Park. Kim et al. (2007a) estimated that there were about 5.33 individuals of roe deer per square kilometer inhabiting Mt. Hallasan National Park, Jeju Island. In addition, Jeon and Kim (2011) estimated the density of roe deer inhabiting Mt. Hallasan National Park as 7.8 individuals $/ \mathrm{km}^{2}$ by citing the research result published by the Research Institute of Environment and Resources of Jeju Special Self-Governing Province in 2009. In July 2013, due to increasing damage of agricultural crops in Jeju Island by roe deer, roe deer was designated as a noxious animal (hazardous animal or pest animal) of the province. Conclusively, we would like to point out the importance in exactly knowing the population dynamics of roe deer on Mt. Hallasan National Park.

It was very interesting to find the evidence for the seedlings of Korean fir being browsed by roe deer was broadcasted at the TV program of the KBS featured in

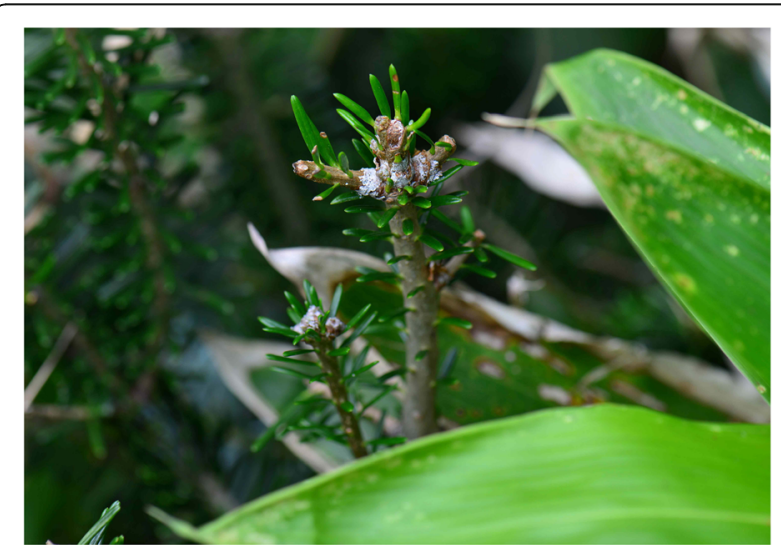

Fig. 4 A photo of the seedling of Korean fir whose stem tips have been browsed (31 July 2016, photo by Eun-Shik Kim)
November 17, 2016, with very close-up scenes that roe deer is devouring the young shoots of Korean fir in early spring inside the volcanic crater, Baekrokdam, located at the summit of Mt. Hallasan (KBS 2016).

The fact that there are very few seedlings taller than $8 \mathrm{~cm}$ in height at the sampling plots indicates that most of the seedlings cannot grow taller than $7 \mathrm{~cm}$ in height because of their increased vulnerability to and with easier exposition to potential browsing by roe deer with their increased size in height.

This indicates that the disturbance in the natural regeneration of seedlings as well as saplings was significantly impacted by the continued browsing of the seedlings from the very early stages of the seedling development by roe deer for the last two to three decades since the restoration and conservation projects of roe deer started in 1987 at the study site, with which we see the ultimate eradication of the natural regeneration of bigger seedlings of Korean fir at the study site.

\section{Frequency distribution and the disturbance in the seedling development of Korean fir by age}

When the ages of the seedlings of Korean fir at the sampling plots were measured, it was quite striking to note that there were almost no seedlings with their ages older than 10 years with exception of 16-year-old seedling ( 1 seedling). In addition, $96.6 \%$ of the seedlings are with their ages in between 2 and 5 years old and $66.2 \%$ of them are with their ages in between 2 and 3 years old. The average age of the seedlings is 3.2 years old (Fig. 5).

It is quite interesting to note that the number of very young seedlings begins to drop very dramatically from 4 years in age. It is also interesting to note that 138 seedlings $(22.4 \%)$ out of 616 young seedlings have the vestiges for being grazed, potentially, by roe deer, with 


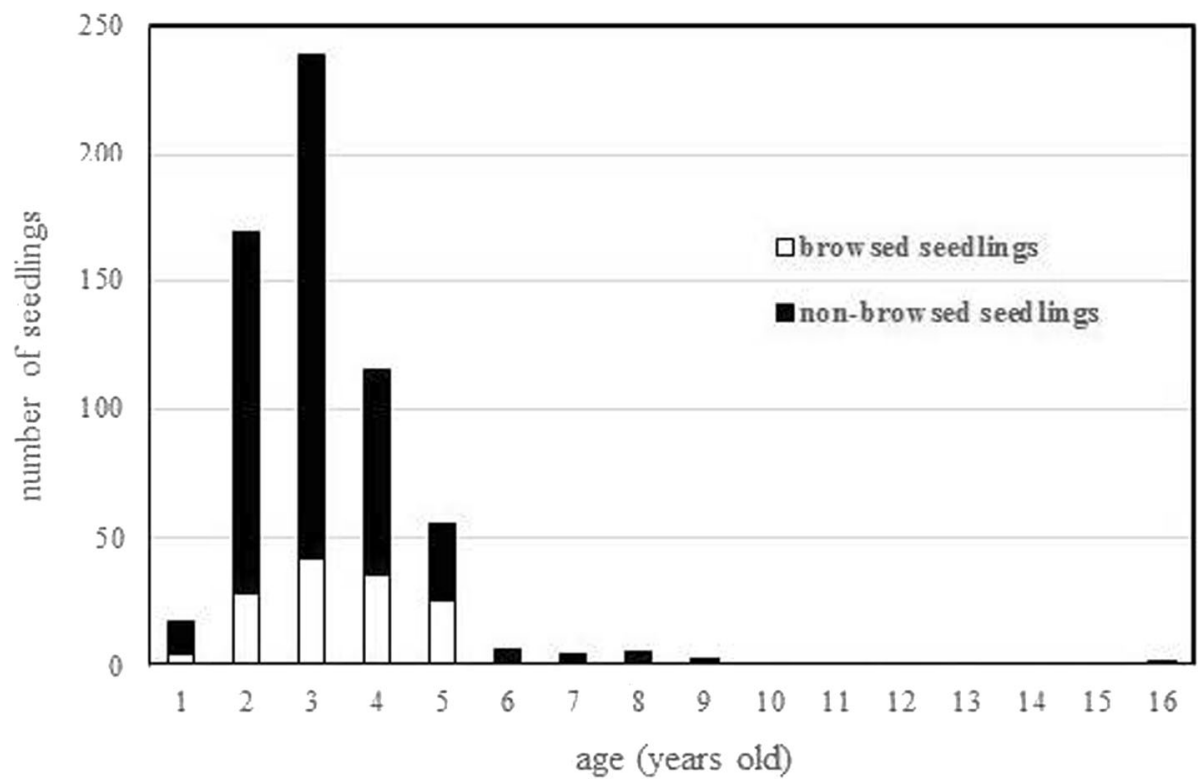

Fig. 5 Frequency distribution and the disturbance in the seedling development of Korean fir by age

their age younger than 5 years old. This strongly suggests that the very young seedlings after just being sprouted from the seeds can be browsed, potentially, by roe deer.

The fact that there are very few seedlings older than 6 years at the sampling plots indicates that most of the seedlings cannot survive more than 5 years in age because of their continuous disposition to the browsing by roe deer. This reassures that the disturbance in the natural regeneration of seedlings as well as saplings was significantly impacted by the continued browsing of the seedlings from the initial stages of seed sprouts, potentially, by roe deer for the last two to three decades since the restoration and conservation projects of roe deer at the study area since 1987, which ultimately eradicated the natural regeneration of bigger seedlings of Korean fir that can be observed at the study site, nowadays.

\section{Distribution patterns of the seedlings of Korean fir by sampling plot}

The average number of seedlings of Korean fir appearing at the sampling plots is 4.93 seedlings per sampling plot.

To understand the distribution patterns in the number of the seedlings of Korean fir appearing each sampling plot, the number of sampling plots and the total number of seedlings appeared at the sampling plots is suggested in Table 1.

On the appearance of the seedlings at the sampling plots, there are a few points of interest to note. Firstly, at $56 \%$ (70 out of 125 plots) of the sampling plots, there are no seedling appeared, which indicates that there is big variation in the regeneration of the seedlings of
Table 1 Distribution patterns in the number of seedlings of Korean fir for the sampling plots

\begin{tabular}{|c|c|c|c|}
\hline $\begin{array}{l}\text { Number of } \\
\text { seedlings } \\
\text { appearing } \\
\text { per sampling } \\
\text { plot }\end{array}$ & $\begin{array}{l}\text { Number of } \\
\text { sampling } \\
\text { plots }\end{array}$ & $\begin{array}{l}\text { Total number } \\
\text { of seedlings } \\
\text { appeared }\end{array}$ & $\begin{array}{l}\text { Percentage of the total } \\
\text { number of seedlings } \\
\text { appeared }(\%)\end{array}$ \\
\hline 0 & 70 & 0 & 0.00 \\
\hline 1 & 19 & 19 & 3.08 \\
\hline 2 & 7 & 14 & 2.27 \\
\hline 3 & 7 & 21 & 3.41 \\
\hline 4 & 3 & 12 & 1.95 \\
\hline 5 & 1 & 5 & 0.81 \\
\hline 6 & 2 & 12 & 1.95 \\
\hline 8 & 2 & 16 & 2.60 \\
\hline 12 & 2 & 24 & 3.90 \\
\hline 16 & 2 & 32 & 5.19 \\
\hline 17 & 1 & 17 & 2.76 \\
\hline 20 & 1 & 20 & 3.25 \\
\hline 21 & 1 & 21 & 3.41 \\
\hline 22 & 1 & 22 & 3.57 \\
\hline 27 & 1 & 27 & 4.38 \\
\hline 30 & 1 & 30 & 4.87 \\
\hline 33 & 1 & 33 & 5.36 \\
\hline 66 & 1 & 66 & 10.71 \\
\hline 95 & 1 & 95 & 15.42 \\
\hline 130 & 1 & 130 & 21.10 \\
\hline Sum & 125 & 616 & 100.00 \\
\hline
\end{tabular}


Korean fir at the study site. Secondly, there are sampling plots where more than 50 seedlings appear, which indicates that there are patterns of diverse and uneven distribution of seedlings at the study site. Thirdly, the fact that there is a sampling plot where 130 individual seedlings appear as a clump further indicates that the germination of seeds of Korean fir are not limited depending on the conditions of the study site. All of these suggest that there are many seeds being sprouted and joining in the pools of young seedlings at the study site and that more extensive eco-physiological studies are needed to check the dynamics of seedling development including the germination of the seeds and establishment of the seedlings at the Korean fir forests on Mt. Hallasan.

\section{Height growth regressed with the age of the seedlings of Korean fir}

In order to check the relationships between the age and the height growth of the seedlings, the height of the seedlings was regressed with the age of the seedlings.

When 138 seedlings with vestiges whose tops potentially being browsed by roe deer were included in the regression analysis (Fig. 6), we can find a very significant and positive relationship between them represented by the equation,

$$
y=1.162 x+0.597\left(r^{2}=0.66, p<0.001\right),
$$

where $x$ represents the age of the seedlings in years and $y$ represents the height of the seedlings in centimeters.

In order to check the relationships only for 478 seedlings of Korean fir with intact stem tips (Fig. 7), a very similar trend was shown between them represented by the equation,

$$
y=1.198 x+0.408\left(r^{2}=0.67, p<0.001\right) .
$$

When all the 616 seedlings were included in the regression analysis, we can also find a very significant and positive relationship between them represented by the equation,

$$
y=1.194 x+0.435\left(r^{2}=0.67, p<0.0001\right) .
$$

From these equations, it becomes clear that the seedlings of Korean fir at the study site are growing very slowly in height with the speed of $1.2 \mathrm{~cm} /$ year for at least first 10 years or more. This indicates that the average height of the 10-year-old seedlings of Korean fir is about $12 \mathrm{~cm}$ at the study site, which also supports the argument that Korean fir is a very slow growing tree species during its seedling stage.

As there is a big gap in the bigger and older seedlings taller than $35 \mathrm{~cm}$ in height and older than 16 years in age potentially being disturbed with the grazing by roe deer at the forest, it is difficult to maintain whether Korean fir is a shade-tolerant tree species during its early stage of natural regeneration from the observation carried out through this study. But we can argue that the possibility for Korean fir to be the shade tolerant tree species cannot be ruled out, however.

The occurrence of the seedlings of Korean fir and the relationships with other environmental factors of the study site

To understand the relationship between the occurrence of seedlings of Korean fir and the environmental factors of the study site, the steps to take are, first, to measure

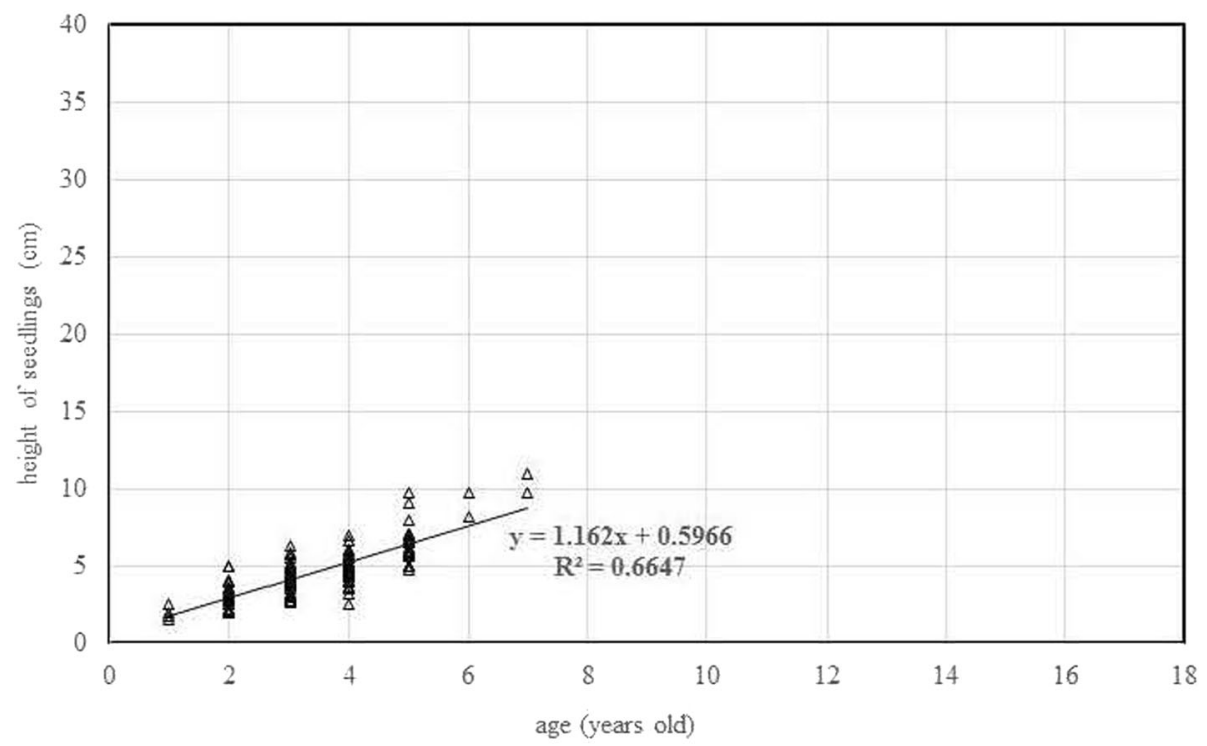

Fig. 6 A linear regression model between the age and the height for 138 seedlings with vestiges which tops potentially being browsed by roe deer 


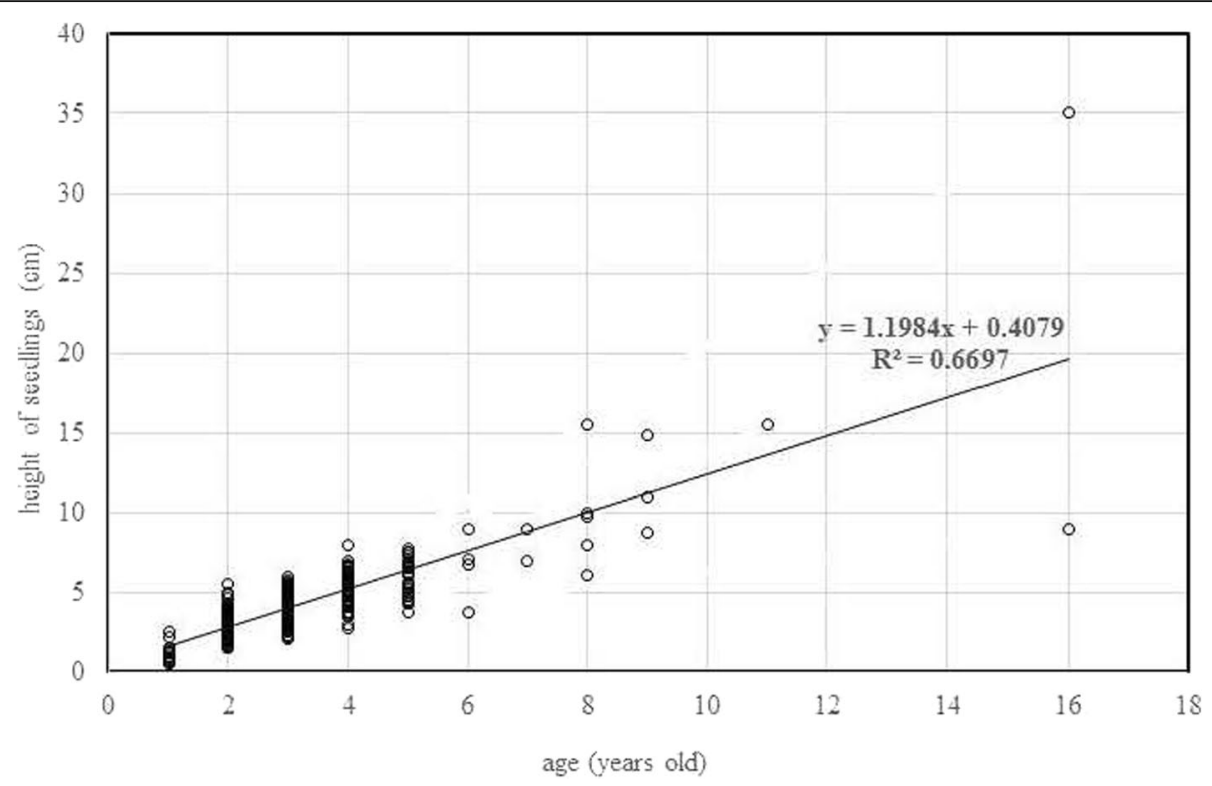

Fig. 7 A linear regression model between the age and the height for 478 seedlings of Korean fir with intact stem tips

and quantify the site environmental factors for each of the sampling plots and, second, to examine the relationships among them by applying the correlation analysis. In addition, as the occurrence of Jeju dwarf bamboo is considered to negatively affect the development of the seedlings of Korean fir at the study site, the coverage and the average height of the community of Jeju dwarf bamboo as well as the frequency and the number of the seedlings of Korean fir occurring at the study site were also measured and their relationships among them were also examined.

\section{Site environmental factors and the relationships among them}

Basic statistics for the site environmental factors to be related to the seedling development of Korean fir are suggested in Table 2.

The rate of rock exposure was positively correlated with slope $(r=0.28, p=0.002)$, which indicates that the higher the slope, the higher the rate of rock exposure at the study site. The rate of canopy gap is negatively correlated with the rate of rock exposure $(r=-0.29, p=$ $0.001)$, which indicates that the higher the rates of rock exposure, the lower the rates of canopy gap at the study site. There is no significant correlation between the rate of canopy gap and the slope rate $(r=0.04, p=0.64)$, however.

\section{Coverage of Jeju dwarf bamboo and its relationships with site environmental factors}

As Jeju dwarf bamboo is growing at all the sampling plots, the frequency of Jeju dwarf bamboo is all the same at all the plots and shows no variations in them among the plots. So, it is meaningless to relate the frequency of Jeju dwarf bamboo with the site environmental factors at the sampling plots. Instead, the coverage of Jeju dwarf bamboo was related to the site environmental factors at the study site (Table 3 ).

When the coverage data of Jeju dwarf bamboo were related to the data of the site environmental factors, the coverage of Jeju dwarf bamboo is very highly and negatively correlated with the rate of rock exposure $(r=$ $-0.354, p<0.0001$ ), which indicates that lower the rate of rock exposure, more abundant Jeju dwarf bamboo at the study site. It is reasonable to see this trend because there will be more Jeju dwarf bamboo established

Table 2 Basic statistics of site environmental factors for this study

\begin{tabular}{|c|c|c|c|c|c|}
\hline $\begin{array}{l}\text { Site } \\
\text { environmental } \\
\text { factor }\end{array}$ & $\begin{array}{l}\text { Number of } \\
\text { observation }\end{array}$ & Average & $\begin{array}{l}\text { Standard } \\
\text { deviation }\end{array}$ & Minimum & Maximum \\
\hline $\begin{array}{l}\text { Rate of rock } \\
\text { exposure (\%) }\end{array}$ & 125 & 21.5 & 16.7 & 0 & 50 \\
\hline Slope $\left({ }^{\circ}\right)$ & 125 & 14.0 & 7.0 & 5 & 35 \\
\hline $\begin{array}{l}\text { Rate of canopy } \\
\text { gap (\%) }\end{array}$ & 125 & 53.2 & 18.0 & 12 & 92.5 \\
\hline $\begin{array}{l}\text { Average } \\
\text { height of the } \\
\text { population of } \\
\text { Jeju dwarf } \\
\text { bamboo }(\mathrm{cm})\end{array}$ & 125 & 71.4 & 16.7 & 9 & 125 \\
\hline $\begin{array}{l}\text { Coverage of } \\
\text { Jeju dwarf } \\
\text { bamboo }\end{array}$ & 125 & 4.52 & 0.79 & 3 & 5 \\
\hline
\end{tabular}


Table 3 Basic statistics of vegetation data of Korean fir surveyed for this study

\begin{tabular}{llllll}
\hline $\begin{array}{l}\text { Vegetation } \\
\text { factor }\end{array}$ & $\begin{array}{l}\text { Number of } \\
\text { observation }\end{array}$ & Average & $\begin{array}{l}\text { Standard } \\
\text { deviation }\end{array}$ & Minimum & Maximum \\
\hline $\begin{array}{l}\text { Frequency of } \\
\text { Korean fir }\end{array}$ & 125 & 0.43 & 0.50 & 0 & 1 \\
$\begin{array}{l}\text { Number of } \\
\text { seedlings of } \\
\text { Korean fir }\end{array}$ & 125 & 4.93 & 16.25 & 0 & 130 \\
\hline
\end{tabular}

because of higher possibility for Jeju dwarf bamboo to be established in spreading their roots at the sites of lower rock exposure.

In contrast, the coverage of Jeju dwarf bamboo is significantly and positively correlated with the rate of canopy gap ( $r=0.197, p=0.028)$ at the study site, which indicates that the higher the rate of canopy gap of the vegetation, the more abundant the coverage of Jeju dwarf bamboo at the study site because of the higher potential coverage of Jeju dwarf bamboo promoted by higher canopy gap at the study site. It is reasonable to postulate that Jeju dwarf bamboo can establish better at the study site of higher canopy gaps due to higher potential growth.

It is also interesting to note that the coverage of Jeju dwarf bamboo is significantly and negatively correlated with the slope of the study site $(r=-0.268, p=0.0025)$, which indicates that Jeju dwarf bamboo favors the site of lower slope than that of higher slope because of better environment for the establishment of Jeju dwarf bamboo at the study site.

When the relationships between the height of Jeju dwarf bamboo and the site environmental factors are examined, the height of Jeju dwarf bamboo is highly and positively correlated with the rate of canopy exposure $(r$ $=0.266, p=0.0027$ ), which indicates that Jeju dwarf bamboo grows higher at the study site of higher canopy gaps than that of lower canopy gaps because of better environment for Jeju dwarf bamboo to establish at the study site. It is interesting to note that the height of Jeju dwarf bamboo is not significantly correlated with both the rate of rock exposure $(r=-0.05, p=0.59)$ and slope $(r=0.11, p=0.21)$, however.

\section{Occurrence of the seedlings of Korean fir and the relationships with site environmental factors}

The frequency of Korean fir is very highly and positively correlated with the rate of rock exposure $(r=0.32, p=$ $0.0002)$, which indicates that the higher the rate of rock exposure, the more frequent Korea fir seedlings at the study site. It is reasonable to see this trend because, at the sites of higher rate of rock exposure, there will be fewer Jeju dwarf bamboo established not only because of lower possibility for Jeju dwarf bamboo to spread their roots due to lack of soil layer but also because of higher possibility for the seedlings of Korean fir to be established with lower competition with Jeju dwarf bamboo.

In contrast, the frequency of the seedlings of Korean fir is highly but negatively correlated with the rate of canopy gap $(r=-0.29, p=0.001)$, which indicates that the lower the rate of canopy gap, the more frequent the seedlings of Korea fir at the study site. This may indicate that the occurrence of the seedlings of Korean fir can be limited, at the site of higher rate of canopy gap, because of more occurrence of Jeju dwarf bamboo under the higher rate of canopy gap. This situation can limit the development of seedlings of Korean fir at the study site, which was confirmed by the positive relationship between the coverage of Jeju dwarf bamboo with the rate of canopy gap explained before.

The number of seedlings of Korean fir occurring at the sampling plots is very highly and positively correlated with the rate of rock exposure $(r=0.34, p<0.001)$, which indicates that the higher the rate of rock exposure, the higher the number of seedlings of Korean fir occurring at the study site. The number of seedlings of Korean fir occurring at the sampling plots shows insignificant relationships with the slope of the site $(r=0.15$, $p=0.09)$, the rate of canopy exposure of the site $(r=$ $-0.15, p=0.09$ ), and the coverage of the community of Jeju dwarf bamboo $(r=0.15, p=0.10)$. It is very interesting to note that the number of the seedlings of Korean fir occurring at the sampling plots shows very low correlation with the average height of the population of Jeju dwarf bamboo $(r=-0.01, p<0.88)$, which indicates that the seedlings of Korean fir can occur regardless of the coverage and the average height of the population of Jeju dwarf bamboo, which are the indicators of the presence and the abundance of Jeju dwarf bamboo at the study site.

\section{General discussion}

Throughout this paper, we tried to address some issues of importance on the regeneration of Korean fir tree species on higher altitude forests of Mt. Hallasan $\mathrm{Na}$ tional Park, Jeju Island, Korea.

Kim et al. (2016) reported that there exist gaps in the regeneration of saplings and small understory trees for more than last two decades at 5 ha plot at this study site and suggested that there are two important time periods for the disturbance being made at the study site. We suggest that the results of this study support the argument that there exist even bigger gaps in the regeneration of seedlings of Korean fir at this 5 ha study site.

It became clear that there are strong evidences that the regeneration of the seedlings of Korean fir is being disturbed in earlier stage of their development and the seedlings with their size taller than $35 \mathrm{~cm}$ in height and 
those older than 16 years in age have been eradicated at the study site. For the seedlings with their size shorter than $8 \mathrm{~cm}$ in height and with their age younger than 6 years old have the vestiges potentially being browsed by roe deer.

This indicates that the natural regeneration of Korean fir tree species is strongly disturbed for the seedlings potentially being browsed from very early stage of their regeneration by roe deer at the study site, which can be the major factor affecting the disturbance in the natural regeneration of the seedlings of Korean fir forest on Mt. Hallasan National Park.

The browsing of the seedlings of Korean fir by roe deer is thought to be the first candidate of major causal factors that can disturb the natural regeneration of Korean fir from very early stage of the seedling development. So, as it is thought to be very important to prevent for the seedlings to be browsed by roe deer at the study site, there should be some measures devised to stop the seedlings of Korean fir being browsed by roe deer.

On the issues related to mechanisms and processes for the successful regeneration of Korean fir at the study site, Kim et al. (2016) suggested ungulate browsing as the potentially the most powerful disturbing factor and further extended the discussion to the potential interactions with Jeju dwarf bamboo, another powerful disturbing factor, inhibiting the regeneration of the Korean fir at the study site and the measures to take and further studies to be carried out. Readers are referred to some more specifics of the discussion for the restoration of firs and other tree species carried out at many forests of the world (Hester et al. 2000, Kay and Bartos 2000, Halpern 2001, Takahashi et al. 2001, Narukawa and Yamamoto 2002, Ito and Hino 2004, Taylor et al. 2004, Dobrowolska 2008, Doležal et al. 2009, Pellerin et al. 2010, Nagaike et al. 2014, Bottero et al. 2015). It is worth to pay due attention to measure appropriate vegetation indices on forest ecosystems impacted by deer (Iijima and Nagaike 2015).

The results of this study indicate that browsing of the seedlings, potentially, by roe deer is disturbing seriously the natural regeneration of the seedlings of Korean fir at this stage. If this kind of browsing is allowed to continue, succession of Korean fir forest will be halted and Korean fir forest will disappear from higher altitude forest of Mt. Hallasan. In order to reverse this kind of disturbance to and to promote the natural regeneration of the seedlings of Korean fir, special attention should be paid in the mechanisms of the disturbance in the browsing of the seedlings of Korean fir, potentially, by roe deer at the forest (Kim et al. 2016).

Conclusively, the most important factor that disturbs the regeneration of the seedlings of Korean fir on Mt. Hallasan
National Park is, potentially, due to the browsing by roe deer. Therefore, the authors think the follow-up studies are needed on the dynamics of Korean fir forest on Mt. Hallasan National Park.

1. It is necessary to identify the cause of the disturbance as to whether the germination of seeds is limited and the number of seedlings is reduced due to certain factors, especially in the process of seedlings becoming saplings including germination of Korean fir seeds.

2. To draw an overall knowledge of the regeneration status of Korean fir forest, studies should be further extended to other sites of Korean fir of different aspect and different elevation on Mt. Hallasan National Park.

3. Exclosure/enclosure experiments with different density of roe deer should be urgently carried out to better understand the influence and the mechanism of the browsing of Korean fir by roe deer should be carried out with installation of fences around the forests of Korean fir.

4. In addition, the process and mechanism of interactions between the natural regeneration of the seedlings of Korean fir and the surrounding plant species including Jeju dwarf bamboo and other plant species of interests for the conservation of biodiversity should be further studied to promote the status of biodiversity and ecosystem sustainability in Korean fir forest.

5. Most of all, it is very important to know better the population dynamics of roe deer and the interactions between vegetation and roe deer on Mt. Hallasan National Park.

\section{Conclusions}

Throughout this paper, we tried to address some issues of importance on the disturbance in the regeneration of Korean fir at the understory vegetation of higher altitude forests of Mt. Hallasan National Park, Jeju Island, Korea. It became clear that there are strong evidences that the regeneration of the seedlings of Korean fir are strongly being disturbed at very earlier stage of their development. There are almost no seedlings with their size taller than $32 \mathrm{~cm}$ in height and with their age older than 16 years old. For the seedlings with their size shorter than $8 \mathrm{~cm}$ in height and with their age younger than 6 years old have the vestiges being browsed by roe deer. This indicates that the natural regeneration of Korean fir tree species is strongly disturbed for the seedlings being browsed from very early stage of their regeneration by roe deer at the study site, which is the main mechanism of the disturbance in the natural regeneration in the seedlings of Korean fir on Mt. Hallasan National Park. The browsing of the seedlings of Korean fir by roe deer is thought to be the major factor (or cause) that disturbs the natural regeneration of Korean fir from very 
early stage of the seedling development. So, as it is very important to prevent for the seedlings from browsing by roe deer at the study site, there should be some measures devised to stop the seedlings of Korean fir being browsed by roe deer. Interestingly, the results of this study indicate that the presence of the seedlings of Korean fir is not significantly affected by the coverage and the mean height of the community of Jeju dwarf bamboo of the study site. This implies that the regeneration of the seedlings of Korean fir is not much affected by the presence of Jeju dwarf bamboo. Most of all, the results of this study indicate that the browsing of the seedlings by roe deer is disturbing seriously the natural regeneration of the seedlings of Korean fir at this stage. If this kind of browsing is allowed to continue, succession of Korean fir forest will be halted and Korean fir forest will disappear from higher altitude forest of Mt. Hallasan. In order to reverse this kind of disturbance to and to promote the natural regeneration of the seedlings of Korean fir, special attention should be paid in stopping the browsing of the seedlings of Korean fir by roe deer at the forest. The authors think it is needed for the managers of the forest to install fences around the forest area where the seedlings of Korean fir should be protected from the browsing by roe deer. Exclosure experiments as well as enclosure experiments of different densities of browsing should be carried out. In addition, treatment with different densities of Jeju dwarf bamboo should also be included in the experiment. Most of all, it is very important to know better the population dynamics of roe deer and the interactions between vegetation and roe deer on Mt. Hallasan National Park. By studying these, we are hoping that the results of this study could give important clues in understanding current status of the regeneration, the problems in disturbing the regeneration, and potential clues for overcoming the problems in the regeneration of Korean fir on Mt. Hallasan, Jeju Island, Korea.

\section{Abbreviations}

ASL: Above sea level; CBIS: Climate-sensitive Biological Indicator Species; DBH: Diameter at breast height; IUCN: International Union for Conservation of Nature; KBS: Korea Broadcasting System; KEITI: Korea Environmental Industry \& Technology Institute; MOE: Korea Ministry of Environment; SAS: Statistical Analysis System; UNESCO: The United Nations Educational, Scientific and Cultural Organization

\section{Acknowledgements}

This study was supported by the Korea Ministry of Environment (MOE) through the Korea Environmental Industry \& Technology Institute (KEITI) as the The Converging Technology Program (2013000210001, Development of a Sensor-Network Based Platform System Technology for Monitoring Sub-Alpine Ecosystems on Climate Change in Korea) and also supported by Research Program of Kookmin University in Korea.

\section{Funding}

Not applicable.

\section{Authors' contributions}

ESK coordinated the research, carried out statistical analyses, drafted the article, and submitted the article to the journal. JWL carried out major field studies, collected and compiled data, and is responsible for the quality of the data for this study. IJC, WL, JC, CHO, SHL, and YSK helped various aspects of this study including study design, data collection, field survey, data analyses, drafting manuscript, and reviewing the manuscript. All authors read and approved the final manuscript.

\section{Competing interests}

The authors declare that they have no competing interests.

\section{Consent for publication}

Not applicable.

Ethics approval and consent to participate

Not applicable.

\section{Publisher's Note}

Springer Nature remains neutral with regard to jurisdictional claims in published maps and institutional affiliations.

\section{Author details}

'Department of Forestry, Environment, and Systems, Kookmin University, Seoul 02707, Republic of Korea. ${ }^{2}$ Department of Forest Resources, Graduate School, Kookmin University, Seoul 02707, Republic of Korea. ${ }^{3}$ Department of Biological and Environmental Science, Dongguk University, 32, Dongguk-ro, Ilsandong-gu, Goyang-si, Gyeonggi-do 10326, Republic of Korea. ${ }^{4}$ Institute of Forest Science, Kookmin University, Seoul 02707, Republic of Korea.

Received: 6 March 2017 Accepted: 21 April 2017

Published online: 02 June 2017

\section{References}

Abe, M., Miguchi, H., \& Nakashizuka, T. (2001). An interactive effect of simultaneous death of dwarf bamboo, canopy gap, and predatory rodents on beech regeneration.

Abe, M., Izaki, J., Miguchi, H., Masaki, T., Makita, A., \& Nakashizuka, T. (2002). The effects of Sasa and canopy gap formation on tree regeneration in an old beech forest. Journal of Vegetation Science, 13, 565-574.

Bottero, A., Meloni, F., \& Motta, R. (2015). Ungulate browsing exclusion: effects and medium-term trends in coppice woods in north-western Italy. In: Effects of ungulate browsing on forest regeneration and silviculture. Proceeding of IUFRO International Conference, 14-16 October 2015. Birmensdorf, Switzerland.

Cote, S. D., Rooney, T. P., Tremblay, J. P., Dussault, C., \& Waller, D. M. (2004). Ecological impacts of deer overabundance. Annual Review of Ecology, Evolution, and Systematics, 35, 113-147.

Cutini, A., Chianucci, F., \& Apollonio, M. (2015). Early and long-term impacts of browsing by roe deer in coppiced woods in Central Italy. In: Effects of ungulate browsing on forest regeneration and silviculture. Proceeding of IUFRO International Conference, 14-16 October 2015. Birmensdorf, Switzerland.

Dobrowolska, D. (2008). Growth and development of silver fir (Abies alba Mill.) regeneration and restoration of the species in the Karkonosze Mountains. Journal of Forest Science, 54(9), 398-408.

Doležal, J., Matsuki, S., \& Hara, T. (2009). Effects of dwarf bamboo understory on tree seedling emergence and survival in a mixed-oak forest in northern Japan: a multi-site experimental study. Community Ecology, 10(2), 225-235.

Gill, R. M. A. (1992). A review of damage by mammals in North Temperate Forests: 1. Deer. Forestry, 65(2), 145-169.

Halpern, C. B. (2001). Constraints on conifer regeneration: a review of the literature and a conceptual model for the Pacific Northwest region. HJ Andrews Experimental Forest Long Term Ecological Research. http://andrewsforest.oregonstate.edu/sites/ default/files/ter/research/component/veg/halpern_2001.PDF.

Helms, J. A. (1998). The dictionary of forestry. Society of american foresters (p. 210).

Hester, A. J., Edenius, L., Buttenschøn, R. M., \& Kuiters, A. T. (2000). Interactions between forests and herbivores: the role of controlled grazing experiments. Forestry, 73(4), 381-391.

Hidding, B., Tremblay, J. P., \& Côté, S. D. (2012). Survival and growth of balsam fir seedlings and saplings under multiple controlled ungulate densities. Forest Ecology and Management, 276, 96-103. 
lijima, H., \& Nagaike, T. (2015). Appropriate vegetation indices for measuring the impacts of deer on forest ecosystems. Ecological Indicators, 48, 457-463.

Ito, H., \& Hino, T. (2004). Effects of deer, mice and dwarf bamboo on the emergence, survival and growth of Abies homolepis (Piceaceae) seedlings. Ecological Research, 19, 217-223.

IUCN. (2011). The IUCN Red List of Threatened Species portal site. http://www. iucnredlist.org/details/31244/0. (December 2016).

Jeon, D. U., \& Kim, D. H. (2011). Application of an augmented predator-prey model to the population dynamics of roe deer in Jeju. Korean System Dynamics Research, 12(2), 95-126.

Jo, Y. S., Kim, T. W., Choi, B. J., \& Oh, H. S. (2012). Current status of terrestrial mammals on Jeju Island. Journal of Species Research, 1(2), 249-256.

Kang, M. (2013). Stock-farming folklife and extinction of Mt. Halla sangsan-graze during the Modern and Contemporary. Cheju National University Tamla Culture Research, 43, 137-195 (in Korean with English abstract).

Kay, C. E., \& Bartos, D. L. (2000). Ungulate herbivory on Utah aspen: assessment of long-term exclosures. J Range Management, 53, 145-153.

KBS. (2016). KBS Special (program) on Prologue of UNESCO World Heritage Nature's Time Capsule. KBS (Korean Broadcasting System). http://www.kbs.co. $\mathrm{kr} / 1 \mathrm{tv} / \mathrm{sisa} / \mathrm{k} \_s p e c i a l /$ view/vod/index,1,1_list003,2.html?searchStatus=0\& articlelndex=7\&vosample=\&currentUrl=http://www.kbs.co.kr/1tv/sisa/k_ special/view/vod/index,1,1_list003,2.html. (17 November 2016).

Kerr, G., \& Mackintosh, H. (2012). Long-term survival of saplings during the transformation to continuous cover. Forests, 3, 787-798.

Kerr, G., Mason, B., Boswell, R., \& Pommerening, A. (2002). Monitoring the transformation to continuous cover management. In Forestry Commission Information Note 45. Edinburgh: Forestry Commission.

Kim, E. S. (1994). Decline of tree growth and the changes of environmental factors on high altitude mountains. A report to Korea Science and Engineering Foundation (KOSEF 921-1500-018-2). Report written in Korean.

Kim, Y. S. (1996). Study on the change of forest type and the diameter growth characteristics of Korean fir (Abies koreana Wilson) on Mt. Halla. A thesis for Master of Science, Graduate School, Kookmin University, Seoul, Korea (p. 42) (in Korean with English abstract).

Kim, T. H. (2006). Rates and processes of bare patch denudation in the subalpine grassland of Mt. Halla. Journal of the Korean Geographical Society, 41(6), 657-669 (in Korean with English abstract).

Kim, G. T., \& Choo, G. C. (2000). Comparison of growth condition of Abies koreana Wilson by districts. Kor. J. Env. Eco., 14(1), 80-87 (in Korean with English abstract).

Kim, D. H., \& Hong, Y. K. (2006). A systemic approach for roe deer in Jejudo. Korean System Dynamics Research, 7(2), 191-213 (in Korean with English abstract).

Kim, E. S., \& Kim, Y. S. (2000). Possibility of climate change and simulation of soil moisture content on Mt. Hallasan National Park, Chejudo Island, Korea. Kor. J. Ecol., 23(2), 117-123.

Kim, J. E., \& Kim, M. H. (2001). Study on the native plants preferably fed by the roe deer (Capreolus pygargus tianschanicus) in Mt. Halla. Cheju National University J. of Basic Sciences, 14(1), 63-72 (in Korean with English abstract).

Kim, B. S., Oh, J. G., \& Oh, H. S. (2007a). The current number of its individuals and management plan of roe deer (Capreolus pygargus tianschanicus Satunin) inhabiting Mt. Halla (Hallasan), Jeju Island, Korea. Kor. J. Env. Eco., 21(4), 366-373 (in Korean with English abstract).

Kim, G. T., Choo, G. C., \& Um, T. W. (2007b). Studies on the structure of Abies koreana community at subalpine zone in Hallasan. Kor. J. Env. Eco., 21(2), 161-167 (in Korean with English abstract).

Kim, E. M., Park, Y., Kwon, J. O., Kim, J. E., Kang, C. W., \& Lee, C. B. (2012). Peeling damage of sapling caused by the developing process of roe deer antlers in warm-temperate forests of Jeju Island. Korean Journal of Agricultural and Forest Meteorology, 14(4), 254-259 (in Korean with English abstract).

Kim, E. M., Kwon, J. O., Kang, C. W., Song, K. M., \& Min, D. W. (2013). Home range size and habitat environment related to the parturition of roe deer at warmtemperate forest in Jeju Island using GPS-CDMA based wildlife tracking system. Journal of Korean Association of Geographic Information Studies, 16(2), 65-74 (in Korean with English abstract).

Kim, E. S., Oh, C. H., Park, H. C., Lee, S. H., Choi, J. H., Lee, S. H., Cho, H. B., Lim, W. T., Kim, H. J., \& Yoon, Y. K. (2016). Disturbed regeneration of saplings of Korean fir (Abies koreana Wilson), an endemic tree species, in Hallasan National Park, a UNESCO Biosphere Reserve, Jeju Island, Korea. Journal of Marine and Island Cultures, 5, 68-78.

Koh, J. G., Kim, D. S., Koh, S. C., \& Kim, M. H. (1996). Dynamics of Abies koreana forests. Cheju-Do Island Research, 13, 223-241 (in Korean with English abstract).
Kohyama, T. (1988). Etiology of "Shimagare" dieback and regeneration in subalpine Abies forests of Japan. Geo Journal, 17(2), 201-208.

Kong, W. S., \& Watts, D. (1993). The plant geography of Korea with emphasis on the alpine zones (p. 244). Dodrecht: Kluwer Academic Publishers.

Korea Forest Research Institute. (2015). Conservation of Korean fir forests on Mt. Hallasan, Jeju Island, Korea. Proceedings of the International Symposium on the Conservation of Korean fir forests on Mt. Hallasan, Jeju Island, Korea. Warm Temperate and Subtropical Forest Research Center of the Korea Forest Research Institute. Seogwipo City, Jeju Island, Korea. 29 October, 2015

Lee, T. B. (1970). Abies koreana and its new forms discovered. Jour Korean Forestry Society, 10, 5-6.

Lee, J. (2016). A study on the occurrence of seedlings and saplings of Korean fir (Abies koreana E.H. Wilson) on Mt. Hallasan National Park (A Thesis for Master of Science, Graduate School, Kookmin University, Seoul, Korea. (p. 99) (in Korean with English abstract).

Lee, B. Y., Nam, G. H., Yun, J. H., Cho, G. Y., Lee, J. S., Kim, J. H., \& Oh, K. H. (2010). Biological indicators to monitor responses against climate change in Korea. Korean Journal Plant Taxon, 40(4), 202-207.

Lee, Y. S., Markov, N., Voloshina, I., Argunov, A., Bayarlkhagva, D., Oh, J. G., Park, Y. S., Min, M. S., Lee, H., \& Kim, K. S. (2015). Genetic diversity and genetic structure of the Siberian roe deer (Capreolus pygargus) populations from Asia. BMC Genetics, 16(1), 1-15.

Ministry of Environment, Korea. (2010). 100 Climate-sensitive Biological Indicator Species. http://eng.me.go.kr/eng/web/board/read.do;jsessionid = 664e8olGroGaejJa6 DbEM1aWO5KbYrGpw50hxceyMnkizZHQqYeDY39t7Kb1AmCv.meweb2vhost_ servlet_engine3? pagerOffset $=30 \&$ maxPageltems $=10 \&$ max IndexPages $=10 \&$ searchKey $=\&$ searchValue $=\&$ menuld $=198 \&$ orgC $=\&$ boardld $=48 \&$ board Masterld = 535\&boardCategoryld = \&decorator=. (October 2010).

Nagaike, T., Ohkubo, E., \& Hirose, K. (2014). Vegetation recovery in response to the exclusion of grazing by sika deer (Cervus nippon) in seminatural grassland on Mt. Kushigata, Japan (ISRN Biodiversity Article ID 493495).

Nakashizuka, T. (1988). Regeneration of beech (Fagus crenata) after the simultaneous death of undergrowing dwarf bamboo (Sasa kurilensis). Ecological Research, 3, 21-35.

Narukawa, Y., \& Yamamoto, S. (2002). Effects of dwarf bamboo (Sasa sp.) and forest floor microsites on conifer seedling recruitment in a subalpine forest, Japan. Forest Ecology and Management, 163, 61-70.

Park, H. C., Lee, J. H., Lee, G. G., \& Um, G. J. (2015). Environmental features of the distribution areas and climate sensitivity assessment of Korean fir and Khinghan Fir. Journal of Environmental Impact Assessment, 24(3), 260-277 (in Korean with English abstract).

Pellerin, M., Said, S., Richard, E., Hamann, J. L., Dubois-Coli, C., \& Hum, P. (2010). Impact of deer on temperate forest vegetation and woody debris as protection of forest regeneration against browsing. Forest Ecology and Management, 260, 429-437.

Pepin, D., Renaud, P. C., Boscardin, Y., Goulard, M., Mallet, C., Anglard, F., \& Ballon, $P$. (2006). Relative impact of browsing by red deer on mixed coniferous and broad-leaved seedlings - an enclosure-based experiment. Forest Ecology and Management, 222, 302-313.

Peters, R., Nakashizuka, T., \& Ohkubo, T. (1992). Regeneration and development in beech-dwarf bamboo forest in Japan. Forest Ecology and Management, 55, 35-50.

Potvin, F., Pierre, B., \& Gaetan, L. (2003). The eradication of balsam fir stands by white-tailed deer on Anticosti Island, Quebec: a 150-year process. EcoScience, 10(4), 487-495.

Rooney, T. P., \& Waller, D. M. (2003). Direct and indirect effects of white-tailed deer in forest ecosystems. Forest Ecology and Management, 181, 165-176.

Senn, J., \& Suter, W. (2003). Ungulate browsing on silver fir (Abies alba) in the Swiss Alps: beliefs in search of supporting data. Forest Ecology and Management, 181, 151-164.

Song, J. H., Jang, K. H., \& Hur, S. D. (2010). Variation of seed and germination characteristics of natural populations of Abies koreana Wilson, a Korean endemic species. Journal of Korean Forest Society, 99(6), 849-854 (in Korean with English abstract).

Song, K. M. (2011). Vegetation structure and dynamics of Abies koreana forests on Mt. Halla. A thesis for Doctor of Philosophy, Graduate School, Jeju National University, Jeju, Korea (p. 97) (in Korean with English abstract).

Song, K. M., Kang, Y. J., \& Hyeon, H. J. (2014). Vegetation structure at the slope direction and characteristic of seedlings of Abies koreana in Hallasan Mountain. Journal of Environmental Science International, 23(1), 39-46 (in Korean with English abstract). 
Sprugel, D. G. (1976). Dynamic structure of wave-regenerated Abies balsamea forests in the northeastern United States. Journal of Ecology, 64, 889-911.

Swiss Federal Institute for Forest. (2015). Effects of ungulate browsing on forest regeneration and silviculture. Proceeding of IUFRO International Conference, 14-16 October 2015. Birmensdorf, Switzerland.

Takahashi, K., Homma, K., Vetrova, V. P., Florenzev, S., \& Hara, T. (2001). Stand structure and regeneration in a Kamchatka mixed boreal forest. Journal of Vegetation Science, 12, 627-634.

Takatsuki, S. (2009). Effects of sika deer on vegetation in Japan: a review. Biological Conservation, 142, 1922-1929.

Taylor, A. H., Huang, J., \& Zhou, S. Q. (2004). Canopy tree development and undergrowth bamboo dynamics in old-growth Abies-Betula forests in southwestern China: a 12-year study. Forest Ecology and Management, 200, 347-360.

Taylor, A. H., Jang, S. W. Zhao, L. J., Liang, C. P., Miao, C. J., \& Huang, J. (2006). Regeneration patterns and tree species coexistence in old-growth AbiesPicea forests in southwestern China. Forest Ecology and Management, 223, 303-317.

Tsujino, R., \& Yumoto, T. (2004). Effects of sika deer on tree seedlings in a warm temperate forest on Yakushima Island, Japan. Ecological Research, 19, 291-300.

Waller, D. M., \& Alverson, W. S. (1997). The white-tailed deer: a keystone herbivore. Wildlife Society Bulletin, 25(2), 217-226.

Weisberg, P. J., \& Bugmann, H. (2003). Forest dynamics and ungulate herbivory: from leaf to landscape. Forest Ecology and Management, 181, 1-12.

Wilson, E. H. (1920). Four new conifers from Korea. Journal of the Arnold Arboretum, 1, 186-190.

Wilson, A. D. (1969). A review of browse in the nutrition of grazing animals. Journal of Range Management Archives, 22(1), 23-28.

Woo, K. S., Sohn, Y. K., Ahn, U. S., Yoon, S. H., \& Spate, A. (2013). Jeju Island Geopark - a volcanic wonder of Korea. Berlin: Springer.

\section{Submit your next manuscript to BioMed Central and we will help you at every step:}

- We accept pre-submission inquiries

- Our selector tool helps you to find the most relevant journal

- We provide round the clock customer support

- Convenient online submission

- Thorough peer review

- Inclusion in PubMed and all major indexing services

- Maximum visibility for your research

Submit your manuscript at www.biomedcentral.com/submit
C Biomed Central 